\title{
Hepatic specification of the gut endoderm in vitro: cell signaling and transcriptional control
}

\author{
Rossana Gualdi, ${ }^{1}$ Pascale Bossard, ${ }^{1}$ Minghua Zheng, Yoshio Hamada, ${ }^{2}$ John R. Coleman, and \\ Kenneth S. Zaret ${ }^{3}$ \\ Department of Molecular Biology, Cell Biology, and Biochemistry, Brown University, Providence, Rhode Island 02912 USA; \\ ${ }^{2}$ National Institute for Basic Biology, Okazaki 444, Japan
}

We have studied the initial development of pluripotent gut endoderm to hepatocytes using a tissue explant system from mouse embryos. We not only find cellular interactions that specify hepatic differentiation but also those that block hepatogenesis in regions of the endoderm that normally give rise to other tissues. The results implicate both positive and negative signaling in early hepatic specification. In vivo footprinting of the albumin enhancer in precursor gut endoderm shows that the transcriptionally silent but potentially active chromatin is characterized by occupancy of an HNF-3 site. Upon hepatic specification, a host of other factors bind nearby sites as the gene becomes active. Genes in pluripotent cells therefore may be marked for potential expression by entry points in chromatin, where additional factors bind during cell type specification. The findings also provide insight into the evolutionary origin of different endodermal cell types.

[Key Words: Endoderm; liver; development; transcription; chromatin]

Received March 26, 1996; revised version accepted May 16, 1996.

The mechanisms by which different cell types are specified from gut endoderm have remained elusive, primarily because of the lack of a readily accessible precursor cell population. No pluripotent cell lines have been derived from definitive endoderm, and little is known about how this tissue gives rise to parenchymal cells of the liver, lung, intestine, pancreas, and thyroid. In contrast, much is known about the signaling molecules and transcription factors that control the specification of mesodermal derivatives, largely because of the existence of pluripotent cell lines that can be induced to form either myocytes or adipocytes (Green and Kehinde 1974; Davis et al. 1987; Braun et al. 1989; Edmondson and Olsen 1989; Rhodes and Konieczny 1989; Wright et al. 1989; Freytag et al. 1994; Tontonoz et al. 1994). We have isolated pluripotent gut endoderm from mouse embryos and have investigated how it gives rise to liver versus other tissues.

Reverse genetic studies of regulatory factors specific to endoderm-derived tissues have provided limited clues to the mechanism of cell type specification. For example, hepatocyte nulear factor-3 (HNF-3) and HNF-4 are enriched in adult liver (Lai et al. 1991), they activate numerous liver-specific genes, and they are expressed in presumptive hepatic endoderm (Ang et al. 1993; Monaghan et al. 1993; Sasaki and Hogan 1993; Duncan

${ }^{1}$ These authors contributed equally to this work.

${ }^{3}$ Corresponding author. et al. 1994). HNF-3 $\alpha$, HNF-3 $\beta$, and HNF-3 $\gamma$ contain the winged-helix DNA-binding domain (Clark et al. 1993; Lai et al. 1993), and HNF-4 is an orphan receptor in the nuclear receptor superfamily (Sladek et al. 1990). Homologs of HNF-3 and HNF-4 in Drosophila, encoded by the fork head and HNF-4(D) genes, respectively, are essential for the development of the fly gut (Weigel et al. 1989; Zhong et al. 19931, suggesting an evolutionarily conserved mechanism for endoderm differentiation. In mammals, however, HNF-3 proteins are also expressed in nonhepatic endoderm as well as notochord and floor plate (Ang et al. 1993; Monaghan et al. 1993; Sasaki and Hogan 1993!, and HNF-4 is also expressed in the visceral endoderm of the yolk sac (Duncan et al. 1994). Homozygous inactivation of HNF- $3 \beta$ or HNF- 4 in the mouse leads to early embryonic lethality, prior to the differentiation of hepatic endoderm (Ang and Rossant 1994; Chen et al. 1994; Weinstein et al. 1994). Thus, the developmental function of these proteins in liver and gut specification is unresolved.

Although genetic methods have yet to provide much insight into hepatic specification, experiments with transplanted tissues have revealed critical cell interactions (Zaret 1996). Hepatocytes develop from endoderm lining the presumptive ventral foregut, near the developing heart. At $\sim 9$ days gestation in the mouse, foregut endoderm in contact with cardiac mesoderm proliferates more rapidly, and first $\alpha$-fetoprotein (AFP) and then serum albumin mRNAs become detectable by in situ hy- 
bridization (Shiojiri 1981; Schmid and Schulz 1990; Cascio and Zaret 1991; Shiojiri et al. 1991). By 9.5 days gestation, hepatic endodermal cells migrate into the more posterior mesenchyme of the septum transversum, where they begin to form the liver. Le Douarin (1964, 1975) showed that in the chick, ventral foregut endoderm at the 5-6 somite stages (corresponding to 8-8.5 days of mouse gestation/ developed into glycogen-positive liver tissue 8-10 days after being transplanted to more posterior mesenchyme of 12 somite embryos. However, younger foregut endoderm, from head-fold to 4 somite stages, did not develop into liver unless it was grafted with its adjacent cardiac mesoderm. The posterior-dorsal endoderm from later stages did not develop into liver, even if transplanted with cardiac mesenchyme. These studies indicated that hepatic determination takes place at about the 5 somite stage, it requires contact with cardiac mesoderm, and it can only occur in endoderm from the ventral foregut.

A difficulty in interpreting the transplantation experiments is that assays for hepatic development depend on extensive cell differentiation and tissue outgrowth, processes with more complex requirements than those needed solely for determination or the early steps of differentiation. Consequently, certain developmental potentials, such as those of the posterior-dorsal endoderm, might not have been detected.

In the present study we use primary tissue explants from mouse embryos and reverse transcriptase-PCR (RT-PCR) assays of gene activation to evaluate the mechanism of early hepatic specification. We use the term specification, as suggested by Slack (1991), for studies on tissue interactions required for autonomous development in vitro. As was observed in the chick, we find that hepatic specification of ventral endoderm involves interactions with cardiac mesoderm. However, we also find that other regions of endoderm can initiate hepatic differentiation when freed from inhibitory signals present in the embryo. Having shown that endoderm outside of the foregut is pluripotent, we use in vivo footprinting to investigate how this tissue maintains the potential to activate hepatic genes. The ability to investigate pluripotent cells has allowed us to develop models for both cell signaling and for enabling gene activation in liver specification.

\section{Results}

Hepatic differentiation as an immediate consequence of determination in embryonic development

We assessed hepatocyte differentiation by monitoring the expression of the albumin and AFP genes, the first genes known to be activated in the hepatic lineage. Although previous in situ histological studies indicated that these genes turn on at 9-9.5 days gestation in the mouse (Shiojiri 1981; Schmid and Schulz 1990; Cascio and Zaret 1991; Shiojiri et al. 1991!, 1 day after hepatic determination, the methods used may have failed to detect low-level expression at earlier stages. We therefore used a more sensitive RT-PCR protocol (Rappolee et al. 19881 to assay RNAs in embryo tissues. Mouse embryos were harvested at $8-8.5$ days gestation and grouped by numbers of somites. RNA was isolated from presumptive ventral endoderm (Fig. 1A, region $\mathrm{C}$, presumptive dorsal anterior endoderm (region D), and presumptive dorsal posterior endoderm (region $E$ ) at 4-6 somite and 7-8 somite stages, and was subjected to quantitative RT-PCR assays. The dorsal endoderm segments were isolated from the region close to the midline, to avoid potential contamination from the yolk sac (see Fig. 4B, below). The 3 primer site for reverse transcription and 'PCR was in exon 2 of the albumin transcript, and the 5' primer site was 15 nucleotides downstream of the albumin transcription start (Liu et al. 1988). Primers were also included to detect $\beta$-actin mRNA, as an internal control.

Although no albumin RT-PCR product was detectable in any part of the endoderm in $4-6$ somite embryos (Fig. $1 B$, lanes 3,4 ! a product expected for albumin mRNA, but not genomic DNA, reproducibly occurred with RNA from ventral endoderm of the foregut at the 7-8 somite stage (Fig. 1B, lane 5). No product was obtained with dorsal endoderm throughout the 4-8 somite stages (Fig. $1 B$, lanes 4,6$)$. When the RT-PCR assay was repeated with a 5' PCR site 44 nucleotides upstream of the albumin transcription start, no specific product was detected (data not shown). We conclude that transcription initiation from the albumin promoter occurs in foregut endoderm by the $7-8$ somite stage, a full day before gene activity has been detected by histological methods.

Although in situ assays had found early AFP expression to be specific to the hepatic primordia and yolk sac (Shiojiri 1981; Shiojiri et al. 1991), we found AFP RTPCR products throughout the gut endoderm near the midline, from at least the 4 somite stage onward (Fig. 1C, lanes $1-4$ !. The expression of AFP in dorsal-posterior endoderm may not be surprising, considering that AFP is expressed highly in the gastrointestinal tract later in development (Tyner et al. 1990). In summary, the activation of the albumin gene by the 7 somite stage in the mouse and the determination of hepatic endoderm at the 5 somite stage in the chick (Le Douarin 1975; FukudaTaira 1981) indicates that hepatic differentiation begins as an immediate consequence of cell type determination.

\section{Reconstituting hepatic specification in vitro}

The rapid and selective activation of the albumin gene in response to hepatic determination led us to use albumin mRNA as a marker to investigate specification in vitro. Tissue segments were dissected from mouse embryos at the 4-6 somite stage and cultivated in microwells. In some experiments, ventral foregut endoderm (region C) was excised with adjacent cardiogenic mesoderm (which was not yet beatingl, whereas in others, foregut endoderm was excised alone. Colonies arising from both types of explants had very similar morphologies, except that colonies with cardiac mesoderm nearly always had small clusters of beating cells (Fig. 2B). Whole-mount in 
Figure 1. RT-PCR analysis of endoderm tissues from different somite stage embryos. (A) (Top) Schematic sagittal section through an 8-8.5 day old mouse embryo, in which the foregut and hindgut pockets have just formed. Anterior, left; posterior, right; dorsal, top; ventral, bottom. Endoderm is the darkly shaded segment along the bottom surface and is designated ventral or dorsal based on presumptive tissue position after the gut tube is formed. Cardiac mesoderm is the shaded anterior oval; somites are the rounded rectangles in the middle. Boxed segments labeled $(C-E)$ designate tissue regions isolated. (Bottom) Photograph of a typical embryo showing the designated regions of interest. (B) RT-PCR analysis of albumin and actin mRNAs. RNAs from the tissue segments designated above each lane, at the somite stages shown (lanes 3-6), were analyzed by RT-PCR. Anterior and posterior dorsal endoderm were combined (region D/E) from 4-6 somite embryos. Reaction products were electrophoresed, and an autoradiograph is shown; expected products are shown by arrows. (Lane 1) Size standards; (lane 2) tRNA control; (lanes 7-9) RT-PCR with than actin mRNA in liver and thus the latter the designated amounts of adult liver RNA. Albumin mRNA is much more abundant nonspecific. $(C)$ RT-PCR analysis of AFP and actin mRNAs. As in $B$, except that the positive control mRNA was from a 12.5 day fetal liver (lanes 5,6). The data are representative of three independent tissue isolation experiments, each of which employed tissues pooled from 4-6 embryos per RT-PCR assay. At high AFP mRNA levels a more slowly migrating product is detected (lanes 1,5,6).

situ hybridization analysis showed that as expected (Sassoon et al. 1988), beating cells expressed cardiac $\alpha$-actin mRNA (Fig. 3A). After 2 days in culture, individual colonies were isolated, RNA was extracted, and RT-PCR assays were performed.

When ventral foregut endoderm was cultured without cardiac mesoderm, none of the resulting colonies $(n=17)$ expressed albumin RT-PCR products (Fig. 2C, lane 7;
Table 1). Thus, as seen previously with the chick, we do not observe stable hepatic specification by the 4-6 somite stage. Many of the ventral endoderm colonies $(n=10)$ were within the same microwells as, but not contacting, beating cardiac tissue, indicating that secreted products from the latter were insufficient to induce hepatogenesis. As expected, none of the anterior or lateral segments of cardiac mesoderm $\{n=13$; Fig. $2 \mathrm{~A}$, regions A
Figure 2. Hepatic specification of ventral endoderm in vitro. $(A)$ Schematic view of the embryo, with boxes designating tissue regions used for cell culture. Regions $A$ and $B$ contain presumptive cardiac mesoderm. $(B)$ Photographs of colonies arising from ventral endoderm with (right) or without (left) clusters of beating cardiac cells (bracketed regions). Original magnification is $40 \times$. (C) RT-PCR analysis of albumin RNA in individual colonies from the embryonic regions shown, after 2 days in culture either with $(+)$ or without $|-|$ beating cardiac cells (cardiac) present in the colony. Some of the colonies from cardiogenic mesoderm (regions A and B) did not progress to the beating stage in vitro, as seen by others /Gannon and Bader 1995). (D) RT-PCR analysis of AFP mRNA in colonies from the designated embryonic regions.
A

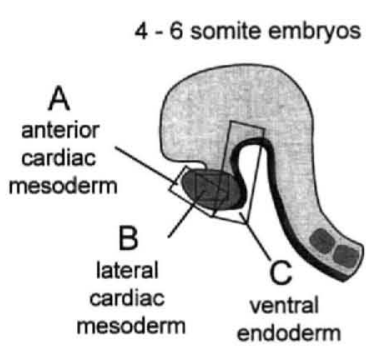

B

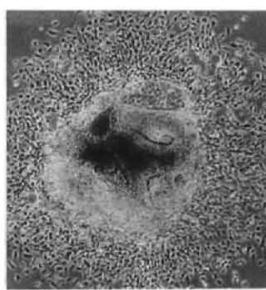

ventral endoderm

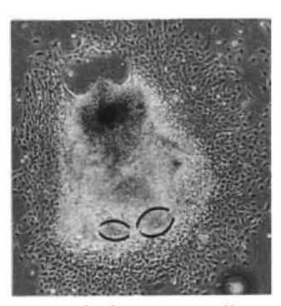

v. endoderm + cardiac
C

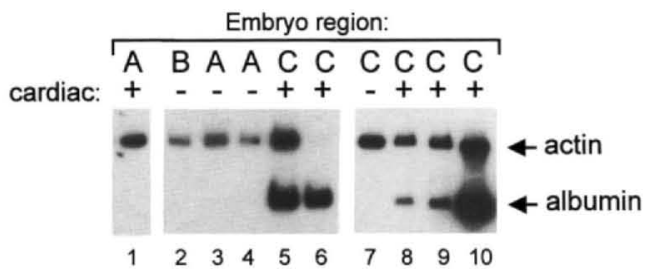

D

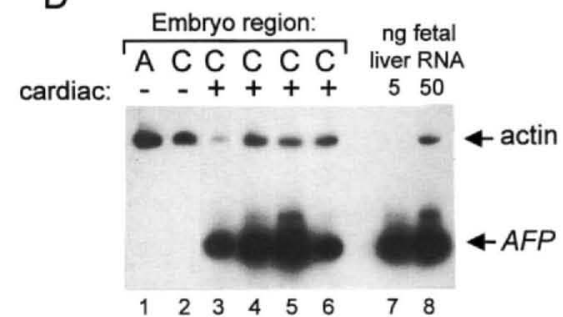



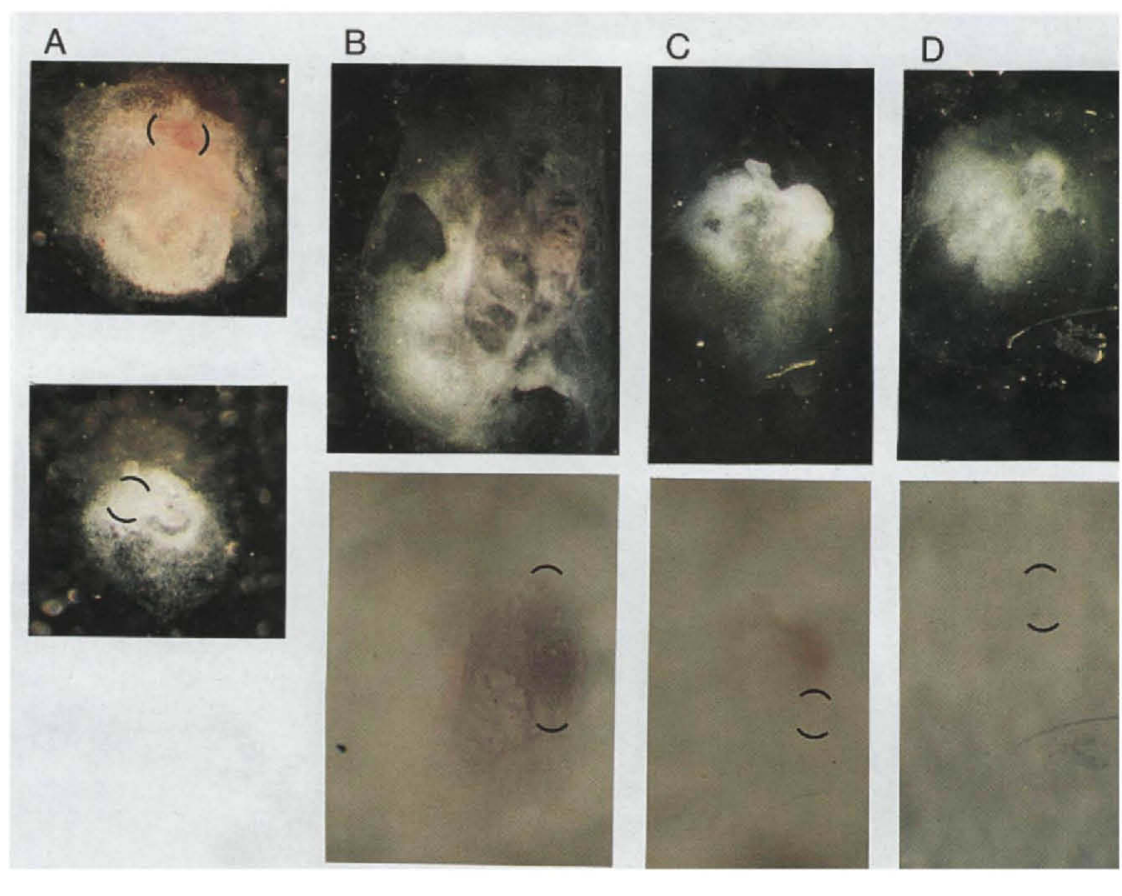

Figure 3. Spatially restricted expression of albumin and cardiac $\alpha$-actin mRNAs cultured ventral endoderm/cardiac mesoderm fragments. Whole-mount in situ hybridization analysis. Beating cell clusters are bracketed; reddish cells are positive for hybridization. $|A|(T o p)$ Cardiac $\alpha$-actin antisense strand probe; (bottom) sense strand probe control; $(B, C)$ albumin antisense probe; $|D|$ albumin sense probe. Colonies in the bottom panels of $B-D$ were photographed with a lighter background to highlight the albumin signals. and $\mathrm{B} \mid$, only some of which progressed to the beating stage, expressed albumin after 2 days in culture (Fig. 2C, lanes 1-4; Table 1). Importantly, all ventral endoderm colonies that contained beating cells exhibited albumin mRNA expression within 2 days $(n=21$; Fig. 2 C, lanes 5,6,8-10; Table 1). Analysis of three such colonies with the albumin upstream primer failed to give rise to specific RT-PCR products (data not shown), indicating authentic start site usage. Three colonies containing both ventral endoderm and beating cardiac mesoderm were examined after a month in culture and found to express albumin mRNA (data not shown), indicating that the induction was stable.

The spatial domains of albumin mRNA expression within ventral endoderm/cardiac mesoderm colonies were examined by whole-mount in situ hybridization. While expressing cells were evident adjacent to beating cardiac clusters, albumin-positive cells clearly extended well beyond the beating areas (Fig. 3B,C).

Strikingly, high levels of AFP RT-PCR products were also observed in all of 13 ventral endoderm/cardiac mesoderm colonies assayed (Fig. 2D, lanes 3-6; Table 1), whereas AFP mRNA was greatly suppressed, relative to $\beta$-actin mRNA, in four colonies from the ventral endoderm region excised alone (Fig. 2D, lane 2). As expected, an AFP RT-PCR product was not observed in colonies of cardiac mesoderm (Fig. 2D, lane 1; Table 1).

We conclude that early liver-specific gene expression is induced from the silent state, such as for albumin, and either maintained or amplified, such as for AFP, by culturing the ventral endoderm in contact with cardiogenic mesoderm in vitro. Both the developmental timing of hepatic specification, relative to embryo somite number, and the dependence on endodermal interactions with

Table 1. Summary of hepatic phenotypes in tissue induction experiments

\begin{tabular}{|c|c|c|c|c|c|c|c|c|c|}
\hline & \multicolumn{2}{|c|}{$\begin{array}{l}\text { Cardiac mesoderm } \\
\text { (region A, B })\end{array}$} & \multicolumn{2}{|c|}{$\begin{array}{c}\text { Anterior ventral } \\
\text { endoderm } \\
\text { (region } \mathrm{C} \text { ) }\end{array}$} & \multicolumn{2}{|c|}{$\begin{array}{l}\text { Anterior dorsal } \\
\text { endoderm } \\
(\text { region D) }\end{array}$} & \multicolumn{2}{|c|}{$\begin{array}{c}\text { Posterior dorsal } \\
\text { endoderm } \\
\text { (region } \mathrm{E} \text { ) }\end{array}$} & \multirow{2}{*}{$\begin{array}{l}\text { Beating } \\
\text { cells }\end{array}$} \\
\hline & - & + & - & + & - & + & - & + & \\
\hline Albumin - & 4 & 9 & 17 & 0 & 10 & 1 & $14^{a}$ & 1 & \\
\hline Albumin + & 0 & 0 & 0 & 21 & 2 & 4 & $9^{b}$ & 3 & \\
\hline $\mathrm{AFP}-$ & 1 & 1 & 4 & 0 & 0 & 0 & $8^{a}$ & 0 & \\
\hline $\mathrm{AFP}+$ & 0 & 0 & 0 & 13 & 4 & 1 & $8^{\mathrm{b}}$ & 0 & \\
\hline
\end{tabular}

Shown are the number of colonies, isolated from designated regions of 4-6 somite mouse embryos, that either expressed or did not express albumin or AFP RNA, as assayed by RT-PCR, after 2 days of culture either with $|+|$ or without $(-1$ beating cardiac mesoderm cells in the colonies (as indicated). The data summarize results from 10 independent tissue isolation and culture experiments.

${ }^{a}$ These samples each include data from eight colonies that also contained some anterior-dorsal endoderm.

${ }^{\text {b}}$ These samples each include data from four colonies that also contained some anterior-dorsal endoderm. 
cardiac mesoderm are remarkably conserved from chick to mouse (Le Douarin 1975).

\section{Hepatogenic potential of gut endoderm that normally} develops into non-liver tissues

Previous studies of 4 somite chick embryos showed that transplanted posterior-dorsal endoderm, which normally forms the intestine, fails to develop into liver tissue even if transplanted with cardiac mesoderm (Le Douarin 1975). These findings led to the hypothesis that dorsal endoderm lacks the potential to develop along the hepatic pathway and that hepatic specification requires potentiation of the foregut endoderm prior to its interaction with cardiac mesoderm (Le Douarin 1975). However, we considered the possibility that dorsal endoderm might be pluripotent with regard to early hepatic and intestinal development and that in the transplantation experiments of Le Douarin, the posterior-lateral mesenchyme of the 12 somite embryo was insufficient to support the advanced stage of liver differentiation required to score a positive histological phenotype. As shown above, RT-PCR analysis of presumptive dorsal endoderm at the 7-8 somite stage failed to detect albumin transcripts (Fig. 1C, lane 6), and similar negative results were obtained with gut endoderm dissected from 9.5 day embryos ( $\sim 25$ somites, Fig. 4A, lane 3). Thus in vivo, the albumin gene remains silent in the dorsal endoderm while it is clearly active in hepatic primordia emanating from the gut at 9.5 days (Fig. 4A, lane 2).

To reassess the developmental potency of dorsal endoderm, we isolated anterior or posterior regions of the midsection of 4-8 somite mouse embryos (Fig. IA), separated the gut endoderm region near the midline from the mesoderm and ectoderm (Fig. 4B), and cultured it with or without presumptive cardiac mesoderm isolated from regions A and B (Fig. 2A). Cell morphology in the resulting colonies was heterogeneous, suggesting the presence of different cell types. After isolating RNA from individual colonies, albumin and AFP expression was assessed.
Surprisingly, we discovered that the dissected dorsal endoderm could activate the albumin gene in culture, even when not in contact with beating cardiac mesoderm. Of 12 colonies of anterior-dorsal endoderm/region D) without beating cardiac cells, 2 scored positive for albumin RT-PCR products (Fig. 4C, lane 8; Table 1). Of 23 colonies of posterior-dorsal endoderm (region $\mathrm{E}$ ) without beating cells, 9 were albumin positive (Fig. 4D, lanes 1,6,7; Table 1). Five of the albumin-positive colonies were in wells that did not have cardiac mesoderm added. All of the albumin-positive colonies from dorsal endoderm gave rise to high levels of AFP RT-PCR products, relative to those for $\beta$-actin, whereas the albumin-negative colonies usually, but not always, expressed low levels of AFP, relative to $\beta$-actin mRNA (data not shown). We conclude that the dorsal endoderm has the potential to initiate hepatic differentiation, at least with regard to early liver gene expression, when its interactions with other dorsal tissues are disrupted.

To directly assess whether dorsal mesoderm and/or ectoderm inhibits hepatogenesis, we isolated ventral endoderm with its adjacent cardiac mesoderm and cultivated it adjacent to embryo midsections containing all dorsal tissues near the midline. After 2 days growth, intermingling of the cells was evident, although the original masses of tissue were still distinguishable (Fig. 5A). We dissected the ventral endoderm portions separately from the dorsal midsections and analyzed RNAs within each by RT-PCR. Of seven ventral endoderm portions that contained beating cardiac cells, five expressed little or no albumin mRNA (Fig. 5B, lanes $3,7,8,9$ ). This result contrasted sharply with the typically high expression of albumin seen in all ventral endoderm/cardiac mesoderm colonies not in contact with dorsal tissues (Fig. 2C). We conclude that dorsal mesoderm and/or ectoderm near the midline is inhibitory to hepatogenesis.

\section{Novel array of enhancer-binding factors at the earliest stages of hepatic differentiation}

Our tissue explant studies indicated that the albumin gene is silent but potentially active in the gut endoderm
Figure 4. Hepatogenesis of dorsal endoderm isolated from embryos. (A) RT-PCR analysis of hepatic primordia (hep. prim.), gut endoderm (gut endo.), and head tissues dissected from 9.5 day mouse embryos (lanes 2-4). (Lane 1) tRNA control; (lane 5) size standards. $(B)$ Posterior dorsal endoderm (arrow) being dissected from an 8-8.5 day embryo midsection. Anterior is to the left. (C,D) RT-PCR analysis of RNA in colonies from anterior-dorsal endoderm (region $D_{\text {; }}$ see Fig. 1A) or posterior dorsal endoderm (region E) of 4-6 somite embryos after 2 days in culture either with $|+|$ or without $|-|$ beating cardiac cells (cardiac) present in the colonies. Lane 14 in $C$ is from a negative control colony of beating cardiac cells.

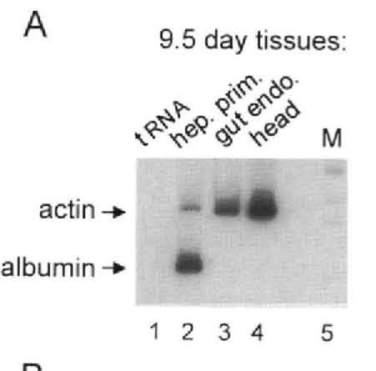

B

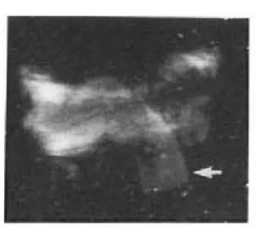

dorsal endoderm dissection

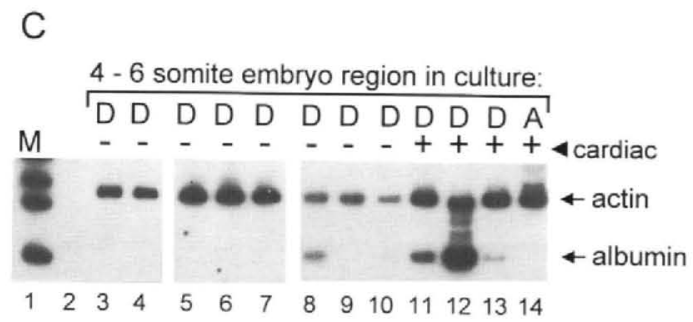

D

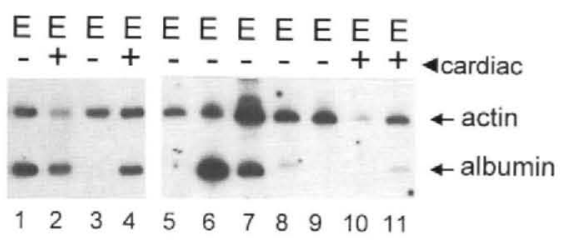


A

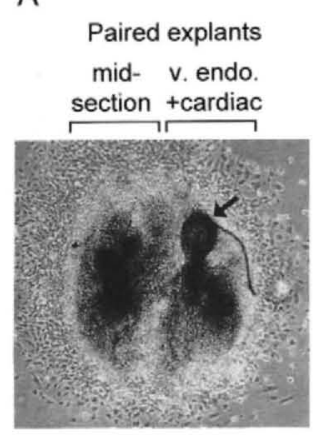

B

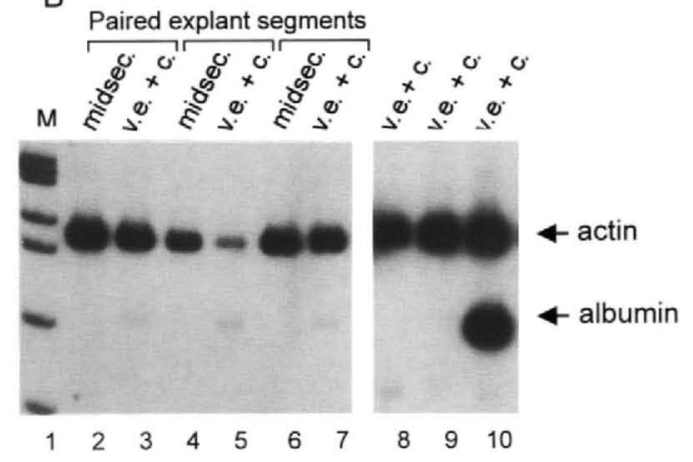

Figure 5. Inhibition of hepatogenesis by midline dorsal tissues. $(A)$ Photographs of colonies arising from juxtaposed tissue explants. The arrow indicates a cluster of beating cells. $(B) \mathrm{RT}$ PCR analysis of halves of colonies from midsections (midsec.) or halves containing ventral endoderm and cardiac cells $(v . e+c$.). The samples in lanes 2 and 3 are from the cells in $A$. and that the gene in hepatic primordia is in its earliest state of activation. To understand the mechanism of potentiation and activation in development, we used an in vivo footprinting protocol to study the albumin gene enhancer, which resides $10 \mathrm{~kb}$ upstream of the promoter. The enhancer confers high-level, liver-specific expression in transgenic mice (Pinkert et al. 1987) and is bound specifically by 12 nuclear proteins in the context of three nucleosome-like particles in liver chromatin (McPherson et al. 1993; Zaret 1995). The most critical enhancer segments in transfected hepatic cells are the eG site, which binds HNF-3, and the eH site, which binds both HNF-3 and the ubiquitous factor NF-1 (Fig. 6C). Mutation of any of these sites inactivates the enhancer (Zaret et al. 1990; Liu et al. 1991; Jackson et al. 1993; Hu and Isom 1994), and thus they define the enhancer's core. In vivo footprinting of adult liver chromatin showed that $\mathrm{eG}$ and $\mathrm{eH}$, as well as eF and eX, sites for two less characterized binding proteins, are occupied within the context of one of the aforementioned nucleoprotein particles (McPherson et al. 1993). We therefore investigated whether early developmental transitions in chromatin occur where multiple factors bind the albumin enhancer core.

Although preliminary experiments indicated that there was insufficient tissue to analyze factors in 8.5 day embryos, we developed a protocol whereby hepatic primordia could be studied when isolated and pooled from $15-20$ embryos at 9.5 days gestation. We already showed that 9.5 day embryos express albumin solely in the hepatic primordia (Fig. 4A). The tissue was disrupted, and the cells were treated with dimethylsulfate (DMS). DMS is permeable to the plasma membrane and methylates guanosine residues in the major groove of DNA unless protected by specifically bound protein; DNA-histone interactions are not detected (McGhee and Felsenfeld 1979|. As a negative control for chromatin in which the albumin gene is not inducible, we analyzed DMS-treated cells from neural tubes dissected from 9.5 day embryos. Although neural tube expresses some HNF-3, it is restricted to the floor plate (Ang et al. 1993). We also established the DMS protection patterns of HNF-3 and NF-1 in vitro using purified protein bound to plasmid DNA. DMS-treated samples were cleaved with piperi- dine, and sites of cleavage mapped by ligation-mediated PCR (Mueller and Wold 1989; McPherson et al. 1993).

As seen in Figure 6A, lane 1, recombinant HNF-3 $\alpha$ protected guanosines 543 and 572 of the bottom strand of the $\mathrm{eG}$ and $\mathrm{eH}$ sites, respectively (Fig. $6 \mathrm{C}$ ). In some experiments, residue 564 of the $\mathrm{eH}$ site was also protected (data not shown). In the hepatic primordia, clear protection reproducibly occurred at all of these bottom strand residues at the two HNF-3 sites (Fig. 6A, cf. lanes 4 and 6). On the top strand, the eG and eH sites in hepatic primordia were protected at positions 536 and 567, respectively, identical to what was observed with purified HNF-3 $\alpha$ in vitro (Fig. 6B, lanes 4,6,7). We conclude that both the $\mathrm{eG}$ and $\mathrm{eH}$ sites of the albumin enhancer are occupied by HNF-3 very early in hepatic development, as they are in the adult liver (McPherson et al. 1993).

Clear evidence for NF-1 occupancy of the eH site in hepatic primordia was seen by protections on the top strand in vivo that matched those with purified protein in vitro (Fig. 6B, lanes 2,6,7). Purified NF-1 failed to exhibit strong protections on the bottom strand in vitro (data not shown) and in vivo (Fig. 6A, lane 4). Methylation protections occurred on both strands of the eF site and on the top strand of the eX site in the hepatic primordia (Fig. 6, A, lane 4, and B, lanes 6 and 7). In contrast, no protections over the enhancer segment were observed in neural tube tissue (Fig. 6A, lane 6). Thus, the five enhancer core sites that are occupied by proteins in adult liver are bound by factors at the earliest stages of hepatic differentiation. In the neural tube, where the albumin gene is not inducible, we found no evidence for specific binding proteins.

Interestingly, in hepatic primordia three strong protections reproducibly occurred on the bottom strand at a new site, designated eY, between the two HNF-3 sites (Fig. 6, A, lane 4, and C). The lack of guanosines prevented top strand analysis. The eY DMS protections were not seen in adult liver (McPherson et al. 1993). Nuclear extracts of 12.5 day embryo hepatocytes, but not extracts from adult liver, contain a protein that binds specifically to a double-stranded eY site oligonucleotide (Fig. 7A, lanes 1-8), whereas both extracts had equal abundance of the albumin promoter CCAAT-binding factor (Fig. 7A, lanes 9-16). The eY-binding activity in 

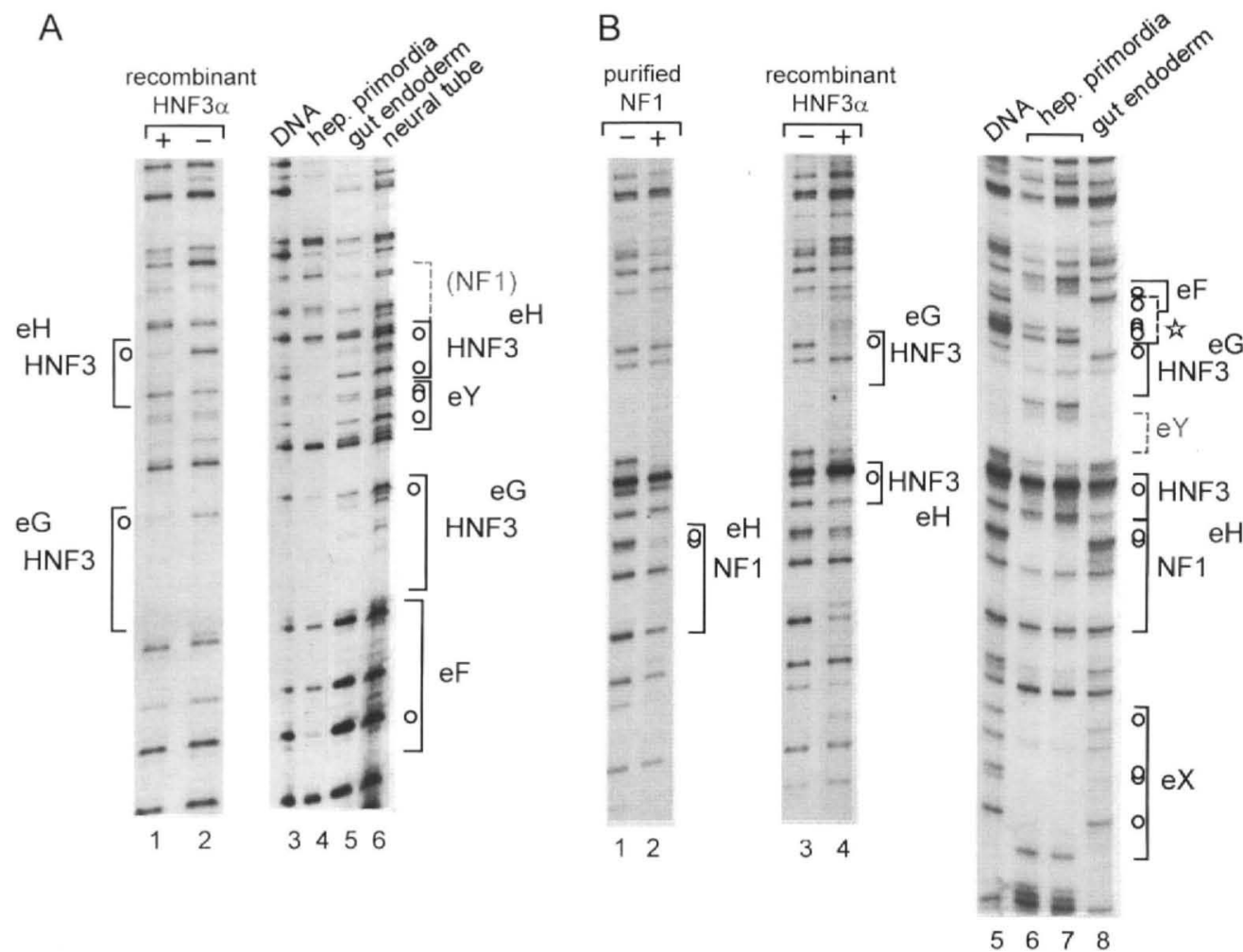

\section{C}

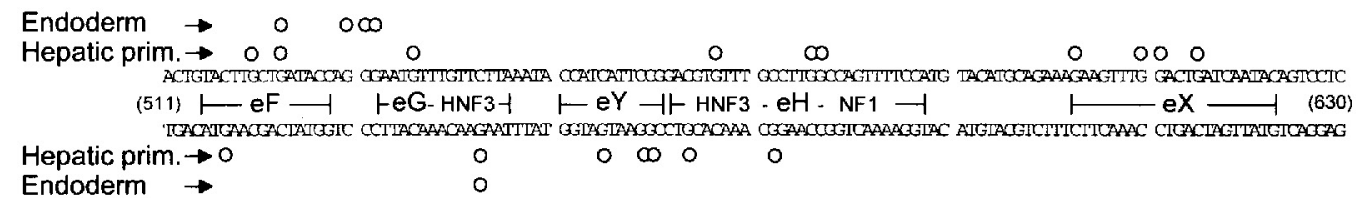

Figure 6. In vivo footprinting of the albumin enhancer in hepatic primordia, endoderm precursor, and nonendoderm tissues. LM PCR analysis of guanosine residues protected from DMS by protein bound either to plasmid DNA in vitro $(A$, lane $1 ; B$, lanes 2,4$)$ or in cells isolated from the designated tissues of 9.5 day embryos $(A$, lanes $4-6 ; B$, lanes $6-8)$. The cleavage patterns of protein-free genomic DNA (DNA) are shown in $A$, lane 3, and $B$, lane 5. $\{A \mid$ Autoradiographs displaying cleavages of the bottom strand of the albumin enhancer; $(B)$ top strand. Guanosine protections by in vitro binding of recombinant HNF-3 $\alpha$ protein (Zaret and Stevens 1995) are shown in $A$, lane 1 , and $B$, lane 4; protections by in vitro binding of NF-1 purified from pig liver (Jackson et al. 1993) are shown in B, lane 2. The extent of factor binding sites determined by DNase I footprinting is shown by brackets. (O) Guanosines protected by bound protein, including the eF and eX sites identified (McPherson et al. 1993), and the eY site, which is specific to hepatic development. The eY site bracket is shown by a broken-line bracket in $B$ because the top strand lacks guanosines. The NF-1 site on the bottom strand is shown by a broken-line bracket because the protein footprints very weakly on this strand in vitro (data not shown) and in vivo (A, lane 4). The starred bracket next to $B$, lane 8 , highlights 4 guanosines protected only in gut endoderm precursor. In $A$, the upper $G$ residue (position 573) of the doublet at 572 and 573 of the eH site is not efficiently cleaved on plasmid DNA in vitro (lanes 1,2 ). The G at position 572 is protected in vitro (lane 2) and in hepatic primordia (lane 4) but not in gut endoderm or neural tube (lanes 5,6$)$. (C) DNA sequence of the footprinted region of the albumin enhancer from position 511 to 630 (Liu et al. 1991). Horizontal brackets indicate sites footprinted by protein. (O) Guanosines protected in the designated 9.5 day embryo tissues. No consistent protections over the enhancer were observed in neural tube.

12.5 day hepatocytes failed to be competed by DNA containing substitutions of the three guanosines protected in vivo (Fig. 7B, lane 4), and the binding activity was confined to the embryo liver and not the head (data not shown). Hu and Isom (1994) reported that AP-1 could bind the albumin enhancer between the eG and $\mathrm{eH}$ sites, and we found that an AP-1 site could compete for eYbinding activity (Fig. 7B, lane 2). However, the eY site did not effectively cross-compete AP-1 binding (Fig. 7B, lane 12), and antibodies to the known c-Fos and c-Jun family members failed to recognize the embryonic eY-binding activity (Fig. 7B, lanes 6-9) while readily perturbing authentic AP- 1 binding in adult liver nuclear extracts (Fig. $7 \mathrm{~B}$, lanes 15-18). Thus, eY is not AP-1. Scanning of the current GenBank transcription factor binding site data base (originated by Ghosh 1990) failed to reveal a se- 
A
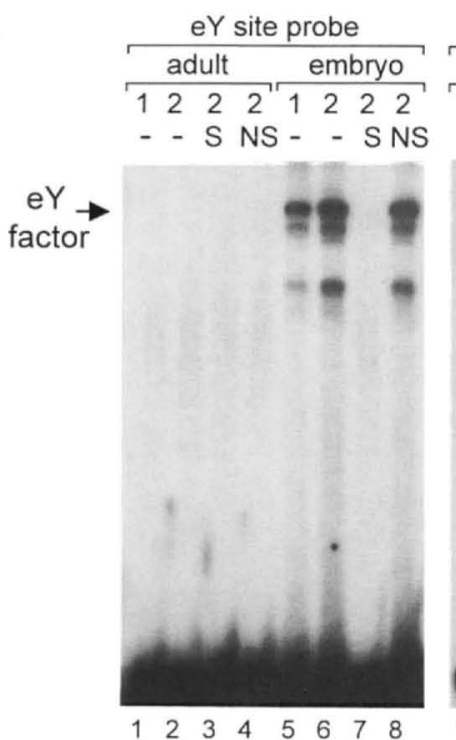

B

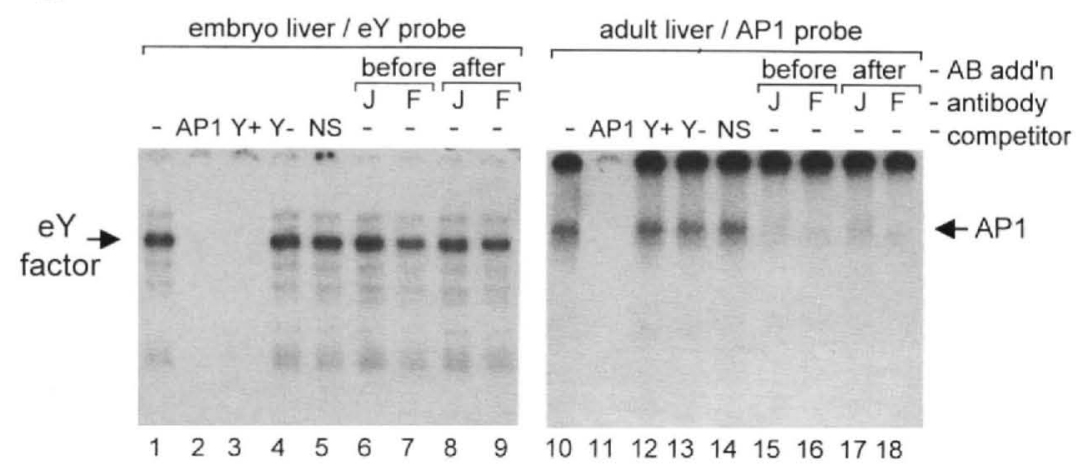

Figure 7. The albumin enhancer $\mathrm{eY}$ site binds a nuclear protein specific to embryonic hepatocytes. Electromobility shift assays with nuclear extracts of hepatocytes from 12.5 day embryo hepatocytes and from adult liver. (A) Adult liver nuclei lack the embryonic eY-binding activity. Designated amounts of protein were incubated in the presence or absence of a 100 -fold molar excess of competitor DNA. Specific competitors (S): eY site, lanes 3,7; CCAAT site, lanes 11, 16. Nonspecific competitors (NS): CCAAT site, lanes 4,8; eG site, lanes 12,16 . The positions of specific protein-DNA complexes are shown by the arrows; free probe is at the bottom. The bands below the one designated eY factor (lanes 6,8 ) were not seen reproducibly (see $B$, lanes 1-9). (B) The eY-binding factor is not AP-1. The indicated nuclear extracts and probes were incubated with a 75 -fold molar excess of the following competitor DNAs: (AP1) consensus AP1 site (lanes 2,11); $(\mathrm{Y}+)$ wild-type $\mathrm{Y}$ site (lanes 3,12); ( $\mathrm{Y}-$ ) $\mathrm{eY}$ site with mutations of the $\mathbf{3}$ guanosine residues contacted in hepatic primordia (lanes 4,13); (NS) nonspecific CCAAT site olig. onucleotide (lanes 5,14). Other nuclear extract samples were incubated with antibodies to all c-Jun $\langle\mathrm{J}\rangle$ or c-Fos $\langle\mathrm{F}\rangle$ family members either before addition of probe (before, lanes $6,7,15,16$ ) or after probe addition (after, lanes 8,9,17,18). The reactions in $B$ were electrophoresed longer than those in $A$; free probe is not shown. The AP1 probe caused some material to be retained in the well, as seen in lanes 10-18. quence highly similar to the eY site. We conclude that a potentially novel protein binds the albumin enhancer and that its activity is confined to the earliest stages of liver gene activation.

\section{Marking the silent but potentially active chromatin in pluripotent endoderm}

We next asked whether factors bind the enhancer core only upon gene activation or if there is a stable, intermediate step where proteins are present prior to activation, marking the enhancer for potential function. We removed gut endoderm from 9.5 day embryos, dissected the tissue free of hepatic buds (Fig. 4A, lane 3), and performed DMS analysis. The only reproducible protection we observed in gut endoderm on the bottom strand of the albumin enhancer was at the eG site for HNF-3 (Fig. 6A, lane 5). On the top strand in gut endoderm, PhosphorImager analysis showed that there was enhanced cleavage of guanosine 536 that was protected by HNF-3 at the eG site in vitro (Fig. 6B, lane 8). The nature of this $\mathrm{G}$ residue protection by HNF-3 in vitro is not clear, as the current crystal structure predicts that the protein would contact the phosphodiester backbone at this nucleotide, not the major groove (Clark et al. 1993). Thus, HNF-3 protection of the residue could vary, depending on the extent of DNA helix distortion caused by other proteins bound nearby. In sum, a protein, possibly HNF-3, occupies the eG site in gut endoderm.

Further analysis of the top strand in gut endoderm revealed none of the other proteins bound in hepatic primordia but, rather, protection of 4 guanosines just upstream of the eG site (Fig. 6B, lane 8, starred bracket). The nature of the binding activity is presently unclear, but the strong protections indicate that the protein must be bound in the majority of cells in the gut endoderm. In conclusion, the silent but potentially active albumin gene in endoderm is marked by occupancy of the enhancer eG site. During hepatic specification, a host of other proteins binds the enhancer in chromatin at the marked site.

\section{Discussion}

We have experimented with mammalian gut endoderm to investigate the earliest events in hepatic specification. 
Previous studies found a lag between the time of hepatic determination, as assessed by tissue transplantation, and the time of cell type differentiation, as assessed by histological assays. Thus, determination and differentiation have been viewed as temporally and functionally distinct processes (Wessells 1977; Gilbert 1994). However, our RT-PCR analysis of mouse endoderm during 4-8 somite stages revealed that liver-specific genes are activated prior to morphological signs of liver differentiation, much earlier than believed from in situ hybridization studies. Similarly, RT-PCR studies of prepancreatic endoderm revealed that insulin and glucagon mRNAs appear about half a day prior to morphological differentiation of the pancreatic diverticulum (Gittes and Rutter 1992). Comparing these data with the stage of determination of the respective cell types, with the available markers it appears that the activation of tissue-specific promoters can be an immediate response to signals that specify cell type. We suggest that RT-PCR analyses might clarify other situations where determination and the onset of differentiation are believed to be distinct, and where promoter activation in embryos is assessed solely by in situ hybridization to mRNA.

The ability of RT-PCR to detect early hepatic differentiation allowed us to develop a tissue explant protocol that did not require extensive cell growth. Although the hepatogenic potential of mouse foregut endoderm was investigated previously (Houssaint 1980), the study employed endoderm from mixed somite stages, where hepatic specification had already occurred. We found that stable hepatogenesis of foregut endoderm from 4-6 somite embryos involves interactions with cardiac mesoderm, precisely as was first shown by Le Douarin (1964) in the chick. We only found hepatic genes activated in colonies of ventral endoderm containing beating cardiac cells. Because albumin is induced in vivo at the 7-8 somite stage (Fig. 1B), just prior to beating, it seems likely that productive endoderm-mesodermal interactions occurred in our cultures before the onset of beating. Gannon and Bader (1995) found that the ventral endoderm promotes the development of cardiac mesoderm to the beating stage.

Ventral endoderm in the same microwells as beating cells, but not contacting them, remained albumin negative and lost AFP expression, indicating that diffusible factors were insufficient to promote hepatogenesis. The ventral endoderm colonies that lacked beating cells expanded until the time of harvest, so the failure to observe differentiation is not readily explained by cell loss. In situ hybridization assays of ventral endoderm/cardiac mesoderm cultures revealed that albumin-positive cells occurred not only adjacent to beating cardiac clusters but also some distance away in the colony. Mechanistically, cardiac mesoderm might secrete inducers regionally into the extracellular matrix; cell contact with endoderm might be required, followed by the layers separating in vitro (as they do in vivo); or cardiac mesoderm might foster interactions among a community of endoderm cells (e.g., Gurdon 1988) that result in hepatogenesis (Fig. 8 , arrow).
Whereas dorsal endoderm in the embryo does not express albumin, colonies of dorsal endoderm from 4-6 somite embryos, when freed from contact with other dorsal tissues, often initiated liver gene expression even in the absence of cardiac mesoderm. We showed further that midline dorsal tissues in culture can inhibit hepatogenesis in juxtaposed ventral endoderm/cardiac mesoderm from the same somite stage. The lack of inhibition of ventral endoderm in the transplantation experiments of Le Douarin (1975) could have been because the 4 somite ventral endoderm and cardiac tissue was transferred to older embryos or because the recipient site was lateral plate rather than the midline. The variable hepatic differentiation of isolated dorsal endoderm we observed, compared to its reproducibility with isolated ventral endoderm, could be attributable to the presence of midline tissues amid colonies of dorsal endoderm. We suggest that the ground state of at least part of the dorsal endoderm is to activate certain hepatic genes and that other dorsal tissues block the hepatogenic pathway while fostering the development of the gastrointestinal tract (Fig. 8).

We speculate that hepatic development may also be intrinsic to the ventral endoderm but is inhibited by other cells in the region. By this model, cardiac mesoderm would block inhibitory effects on or among ventral endoderm cells (Fig. 8, barred lines). An analogy is provided by vulval development in Caenorhabditis elegans, where syncytial hypoderm inhibits certain lateral, fatedetermining signals among vulval precursor cells in the adjacent ventral ectoderm (Sternberg 1988; Herman and Hedgecock 1990|.

The apparent intrinsic hepatogenic ability of the endoderm may be a remnant from primitive metazoans, whose endoderm consisted primarily of cells that like the present liver, metabolized and stored nutrients. Later evolution saw the development of a specialized gut tube,

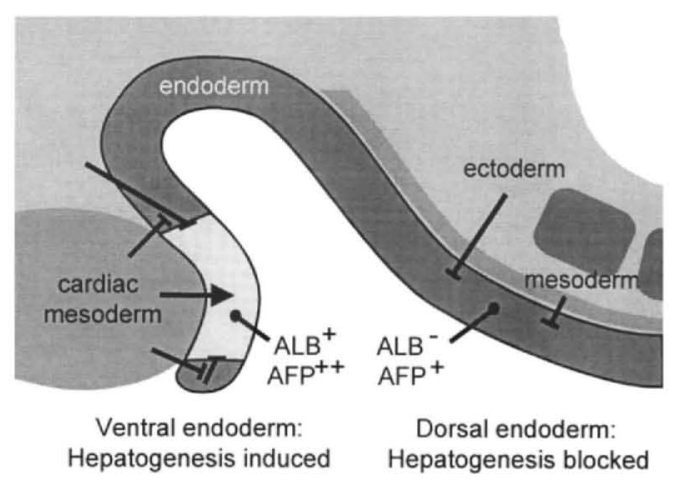

Figure 8. Positive and negative signaling in hepatogenesis. Tissue segments are shown as they are inferred to interact in the embryo. Cardiac mesoderm may induce hepatogenesis (lighter region of endoderm) by positive signaling (arrow) or by blocking inhibitory signals from other ventral tissues (barred lines), thereby allowing hepatogenesis to occur. In the dorsal-posterior region, the sole presence of inhibitory signals results in blockage of the intrinsic hepatogenic capacity of the endoderm. 
which allowed more efficient capture of metabolites. Thus, the original endodermal, partially hepatic phenotype may have been repressed regionally in evolution as other cell types evolved from the gut. Interestingly, when the pancreas is severely damaged by an unusual dietary regimen, pockets of pancreatic cells trans-differentiate into hepatocytes (Yelandi et al. 1990). The hepatogenic potential of this tissue, which is derived in part from dorsal endoderm, appears retained in the adult.

We found that at the earliest stages of hepatic development, but not in its endoderm precursor, a protein binds to the newly discovered $\mathrm{eY}$ site of the albumin enhancer, between the two HNF-3 sites. Although the identity and relevance of the eY factor is not yet clear, the findings underscore the importance of studying the embryo tissue to identify all components of a tissuespecific enhancer. The lack of eY factor binding in adult liver indicates that the enhancer nucleoprotein complex undergoes structural transitions between carlier and later differentiated stages (Fig. 9). As might be expected, the albumin gene is expressed at a much lower level in early liver, compared to the adult (Tilghman and Belayew 1982; Cascio and Zaret 1991). The eY factor therefore could be critical either for initially facilitating ubiquitous factors such as NF1 to bind the enhancer or for keeping enhancer activity low in early liver development.

Occupancy of the albumin enhancer eG site in precursor gut endoderm, where the albumin gene is silent, indicates that the potentially active enhancer is marked (Fig. 91. Given the expression of HNF-3 molecules in the definitive endoderm (Ang et al. 1993; Monaghan et al. 1993; Sasaki and Hogan 1993) and the footprint pattern at the eG site in this tissue, it seems likely that HNF-3
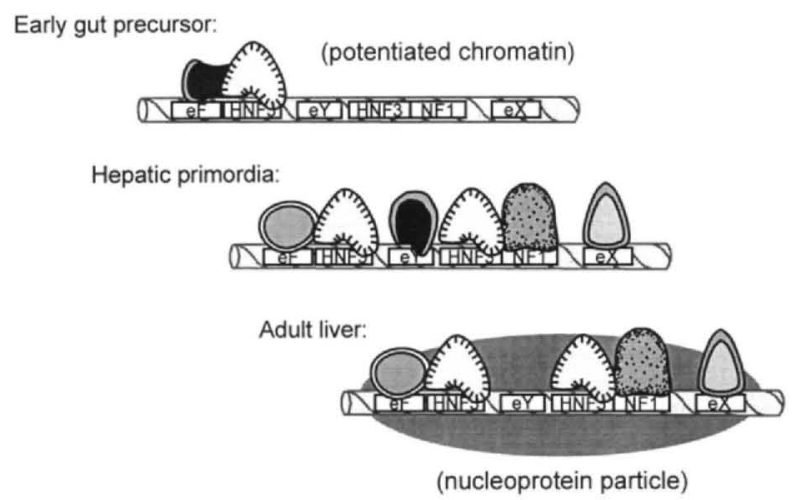

Figure 9. Developmental stages in the formation of an en hancer complex. DNA helices with binding sites labeled are shown with the factors occupying their sites at each of the designated stages of hepatic development. The large oval behind the factors in adult liver indicates that the proteins are part of a nucleoprotein particle that spans $180 \mathrm{bp}$ of DNA |McPherson et al. 1993); the nucleoprotein organization at earlier developmental stages is not known. plays a role in potentiation of enhancer activity. In vitro footprint titrations have shown that HNF-3 $\alpha$ has a 4- to 5 -fold higher affinity for the eG site over the $\mathrm{eH}$ site (Zaret and Stevens 19951, possibly explaining occupancy of $\mathrm{eG}$ but not $\mathrm{eH}$ in the gut endoderm. The DNA-binding domain of HNF-3 resembles the globular core of linker histone (Clark et al. 1993), and the binding of HNF-3/ fork head molecules to the eG site helps position a nuclcosome at the albumin enhancer in a chromatin reconstitution system in vitro (McPherson et al. 1993). The binding of HNF-3, along with the adjacent, as yet uncharacterized, binding activity in gut endoderm, could elicit one of the first steps in chromatin reorganization for gene activation in development. By this means, transcription factor binding to genes in a precursor tissue could simplify the ability of subsequent factors to find their correct target sites in development.

\section{Materials and methods \\ Embryo tissue isolation, cell culture}

$\mathrm{C} 3 \mathrm{H}$ mice were used, and noon of the day of vaginal plug discovery was taken to be 0.5 days gestation; also, somite numbers were used to stage the embryos (Rugh 1968; Theiler 1989|. Embryos were removed from uteri, transferred to dishes containing phosphate-buffered saline (PBS), and dissected free of decidual tissue. At the time of dissection of 4-6 somite embryos, the cardiac region had not started beating. Embryos were transferred to black wax dissecting dishes containing a few drops of warm PBS. Under a dissecting microscope at $60 \times$, using electrolytically etched tungsten needles, the yolk sac, optic lobes, and hindgut were carefully removed and the remaining tissue was moved to fresh PBS. When isolating the presumptive ventral endoderm, all head, upper cardiac lobe, dorsal, and posterior tissues were dissected away from the ventral foregut, and the lower half of the cardiac lobe was either removed or included for cell culture. The desired tissue was transferred to a microcentrifuge tube with PBS or a microwell with medium and pipetted gently to generate several colonies for analysis. When isolating the presumptive dorsal endoderm from midsections near the midline, neural tube and somites were teased away (see Fig. 4B), and the remaining endodermal region was disrupted by pipetting. Tissues were either processed for RNA isolation or cultured separately or together in microwells coated with collagen type I on a glass slide substratum (CoStar) in Dulbecco's modified Eagle medium containing $10 \%$ iron-supplemented calf serum (Hyclone). Collagen substrata were prepared with collagen type I (Collaborative Biomedical Products) by diluting the material in $0.02 \mathrm{~N}$ acetic acid to a concentration of $50 \mu \mathrm{g} / \mathrm{ml}$ and incubating it in microwells at $37^{\circ} \mathrm{C}$ for $1 \mathrm{hr}$. The solution was aspirated and the wells were washed twice with PBS and once with medium. In some experiments, isolated cardiac regions were included in the same microwell as isolated ventral or dorsal endoderm. Microwell slides were incubated in $5 \% \mathrm{CO}_{2}$ at $37^{\circ} \mathrm{C}$. For the experiments in Figure 5, the isolated tissues were physically placed adjacent to one another and checked frequently to be sure they stayed together. Colonies were monitored each day for their growth rates and the presence of beating cells, and all embryos, dissections, and colony morphologies on each day were documented by video photography and digital printouts using either a Wild M3Z dissecting microscope or a 
Nikon Diaphot inverted microscope. After 2 days growth, colonies were either fixed in $4 \%$ paraformaldehyde for in situ hybridization or, for $\mathrm{RT}-\mathrm{PCR}$, lifted from slides with dissecting needles and aspirated with micropipettes. To ascertain that the correct colony was taken, slides were subsequently examined at high power under phase contrast.

\section{RNA isolation, RT-PCR assays, and in situ hybridization}

Whole-mount in situ hybridization was performed on colonies on the slides as described for intact embryos by Wilkinson (1993), with the modifications of Gannon and Bader (1995). Sense and antisense strand RNA probes were labeled with UTPdigoxigenin, used at $0.5-1.5 \mu \mathrm{g} / \mathrm{ml}$, and detected with alkaline phosphatase-conjugated anti-digoxigenin (BMB). Color development was $30 \mathrm{~min}$ to $2 \mathrm{hr}$. The cardiac $\alpha$-actin riboprobc and albumin plasmids have been described (Sassoon et al. 1988; Cascio and Zaret 19911.

RNA was isolated from fresh tissue samples and individual explant colonies as described (Cascio and Zaret 1991). Aliquots were quantitated either in agarose minigels or by RT-PCR with actin-specific primers. Approximately equal amounts of RNA $(\sim 20-50 \mathrm{ng})$ from each colony were subjected to primer extension (Zaret and Stevens 1993), and cDNAs were suspended in 25 $\mu \mathrm{l}$ of distilled $\mathrm{H}_{2} \mathrm{O}$. Half of the primer extension products were subjected to PCR with 10 pmoles of each $3^{\prime}$ oligonucleotide and 10 pmoles of each $5^{\prime}$ oligonucleotide, 0.3 pmole of the latter being phosphorylated with $\left[\gamma^{-32}\right.$ P $\mid$ ATP. Samples were subjected to 28-34 cycles of PCR amplification in a Twin Block System (Ericomp Inc., CA), for $30 \mathrm{sec}$ at $94^{\circ} \mathrm{C}, 1 \mathrm{~min}$ at $60^{\circ} \mathrm{C}$, and $30 \mathrm{sec}$ at $72^{\circ} \mathrm{C}$. Starting from cycle 28 , a $20-\mu \mathrm{l}$ aliquot of the PCR products was removed every three cycles, run on a $6 \%$ polyacrylamide gel, and analyzed by autoradiography. RT-PCR products from at least two different cycle numbers were electrophoresed to ascertain that the reactions analyzed were not saturated by excess template.

When PCR was performed with albumin and actin primers, the latter were added after the first five cycles lexcept in Fig. $4 \mathrm{~A}$, where they were added together|. The sequences of oligonucleotides and expected sizes of RT-PCR products were: 5' albumin, 5'-CCCCACTAGCCTCTGGCAAAAT-3'; $3^{\prime}$ albumin, 5'-CTTAAACCGATGGGCGATCTCACT-3', 127 bp; 5' AFP, 5'CCTCCCAGTGCGTGACGGAGAA-3; 3' AFP, 5'-CACTTC CTCCTCGGTGGCTTCC-3', 89 bp; $5^{\prime} \beta$-actin, 5'-AAAGACCTGTACGCCAACACAGTC- $3^{\prime} ; 3$ ' $\beta$-actin, 5'-GTCATACTCCTGCTTGCTGATCCA-3', 219 bp.

\section{In vivo footprinting of mouse embryo tissues}

Hepatic primordia, gut endoderm, and neural tubes were dissected from different batches of 9.5 day mouse embryos. Each footprinting reaction employed tissues from 15 to 20 embryos pooled into a single tube containing PBS at $4^{\circ} \mathrm{C}$. Tissues were minced to release cells and treated with $0.2 \%$ DMS in PBS for 5 min at room temperature. The samples were immediately transferred to ice, diluted with ice-cold PBS, washed four timcs in ice-cold PBS, suspended in $500 \mu$ l of homogenization buffer (2 M sucrose, $10 \mathrm{~mm}$ HEPES at $\mathrm{pH} 7.6,25 \mathrm{~mm} \mathrm{KCl}, 0.15 \mathrm{~mm}$ spcrmine, $0.5 \mathrm{~mm}$ spermidine, $1 \mathrm{~mm}$ EDTA, $10 \%$ glycerol, $0.5 \mathrm{~mm}$ PMSF, $0.5 \mathrm{mM}$ DTT t, transferred to a $2-\mathrm{ml}$ Wheaton homogenizer, and disnupted with a Teflon pestle. The disrupted cells were layered on $300 \mu \mathrm{l}$ of homogenization buffer and spun at $45,000 \mathrm{rpm}$ for $35 \mathrm{~min}$ at $4^{\circ} \mathrm{C}$ in a TLS55 rotor in a Beckman TL-100 microultracentrifuge. After centrifugation, the nuclear pellet was suspended in a solution of $10 \mathrm{~mm} \mathrm{NaCl}, 10 \mathrm{~mm}$ Tris (pH 7.5), and $3 \mathrm{mM} \mathrm{MgCl}$. The nuclei were lysed with SDS and proteinase $\mathrm{K}$ (Liu et al. 1988) and incubated overnight at $25^{\circ} \mathrm{C}$. DNA was purified by phenol-chloroform extractions, precipitated, and suspended in a solution of $10 \mathrm{~mm}$ Tris $(\mathrm{pH} 8), 1 \mathrm{mM}$ EDTA. In many cases, it was necessary to quantitate DNA by performing PCR reactions with albumin gene primers and comparing products with those of known amounts of mouse liver DNA. Ten nanograms to $1 \mu \mathrm{g}$ of DMS-treated embryonic DNA samples were mixed with $1 \mu \mathrm{g}$ of salmon sperm DNA, which was necessary as a carrier, and mixed with piperidine $10.1 \mathrm{M}$ finall. The samples were incubated at $90^{\circ} \mathrm{C}$ for $10 \mathrm{~min}$ to cleave methylated guanosincs and transferred to dry ice, and piperidine was eliminated by three successive lyophilizations.

LM-PCR analysis was done according to Mueller and Wold (1989) using the buffers of Rigaud et al. (1991) as described by McPherson et al. 11993), except that exponential PCR was increased to $28-32$ cycles. Oligonucleotides for top strand analysis were Nl-T1, N1-T2, and N1-T3, and bottom strand analysis, N1-B1, N1-B2, and N1-B3 |McPherson et al. 1993). After ligation-mediated PCR (LM PCR), DNAs were analyzed on $6 \%$ polyacrylamide $/ 7 \mathrm{M}$ urea sequencing gels. All data shown are representative of at least two independent sets of tissue isolations, and multiple piperidine cleavage reactions and LM PCR assays of cach set. DMS footprinting of factors in vitro employed either HNF-3a protein overexpressed in Escherichia coli and purified to homogeneity (Zaret and Stevens 1995) or NF-1 purificd 400-fold from a pig liver nuclear extract IJackson et al. 19931, using lincarized plasmid DNA bearing the albumin enhancer as a substrate.

\section{Electromobility shift assays of embryo nuclear extracts}

Nuclear extracts were prepared from adult mouse liver as described by Lichtsteiner et al. (1989) and from 12.5 day embryo hepatocytes as described by Ang et al. (1993\}, after hematopoietic cells were depleted by several rounds of mincing the embryo livers and collecting cells adhering to the liver matrix. Electromobility shift assays were performed as described by Jackson et al. (1993). The following oligonucleotides were annealed and filled in with Klenow polymerase to generate probes and competitor DNAs: wild-type eY site $\left(\mathrm{Y}^{+}\right)$, top strand, $5^{\prime}$ AATACCATCATTCCGGA.3', bottom strand, 5' ACGTCCGGAATGATGGT-3'; mutant eY site $\left(\mathrm{Y}^{-}\right)$, top strand, 5'AATACCATAATTGAGGA-3', bottom strand, $5^{\prime}$-ACGTCCTCAATTATGGT-3'. The CCAAT site oligonucleotide was as described by DiPersio ct al. (1991). The following APl site oligonucleotides (Angel et al. 1987) were annealed and labeled with polynucleotide kinase: top strand, 5' CGCTTGATGAGTCAGCCGGAA-3', bottom strand, 5' -TTCCGGCIGACTCATCAAGCG $-3^{\prime}$. The c-Fos polyclonal antibody was reactive to c-Fos, FosB, Fra-1, and Fra-2 proteins, and the c-lun polyclonal was reactive to c-lun, JunB, and JunD proteins (Santa Cruz Biotechnolngyl. Antibodies were either incubated with nuclear extract for $10 \mathrm{~min}$ at room temperature prior to probe addition or added after the probe was mixed with extract, followed by a 20 -min incubation prior to gel loading.

\section{Acknowledgments}

We thank Antonello Pietrangelo, Leslie Rogler for advice on embryo dissections, Kimberly Stevens for HNF-3 $\alpha$ protein, Clifton McPherson for advice on footprinting, Jennifer Bamett Moss for the cardiac actin plasmid, and John Burch, Kimberly Mowry, Gary Wessel, members of the laboratory for helpful comments on the paper, and Carmen Conzález and Susan Sage for help in prepaning the manuscript. P.B. was supported by a postdoctoral 
fellowship from the Ligue Contre le Cancer (France), and the research was supported from a National Institutes of Health grant (GM36477) to K.S.Z.

The publication costs of this article were defrayed in part by payment of page charges. This article must therefore be hereby marked "advertisement" in accordance with 18 USC section 1734 solely to indicate this fact.

\section{References}

Ang, S.-L. and J. Rossant. 1994. HNF-3B is essential for node and notochord formation in mouse development. Cell 78: 561574.

Ang, S.-L., A. Wierda, D. Wong, K.A. Stcvens, S. Cascio, J. Rossant, and K.S. Zaret. 1993. The formation and maintenance of the definitive endoderm lineage in the mouse: Involvement of $\mathrm{HNF} 3 /$ fork head proteins. Development 119: 1301-1315.

Angel, P., M. Imagawa, R. Chiu, B. Stein, R.J. Imbra, H.J. Rahmsdorf, C. Jonat, P. Herrlich, and M. Karin. 1987. Phorbol ester-inducible genes contain a common cis element recognized by a TPA-modulated trans-acting factor. Cell 49: 729-739.

Braun, T, E. Bober, G. Buschhausen-Denker, S. Kotz, K.-H Grzeschik, and H.H. Arnold. 1989. Differential expression of myogenic determination genes in muscle cells: Possible autoactivation by the Myf gene products. EMBO /. 8: 3617-3625.

Cascio, S. and K.S. Zaret. 1991 . Hepatocyte differentiation initiates during endodermal-mesenchymal interactions prior to liver formation. Development 113: 217-225.

Chen, W.S., K. Manova, D.C. Weinstein, S.A. Duncan, A.S. Plump, V.R. Prezioso, R.F. Bachvarova, and J.E. Darnell Jr. 1994. Disruption of the HNF-4 gene, expressed in visceral endoderm, leads to cell death in embryonic ectoderm and impaired gastrulation of mouse embryos. Genes \& Dev. 8: 2466-2477.

Clark, K.L., E.D. Halay, E. Lao, and S.K. Burley. 1993. Co-crystal structure of the HNF3/fork head DNA recognition motif resembles histone $\mathrm{H} 5$. Noture 364: 412-420.

Davis, R.L., H. Weintraub, and A.B. Lassar 1987. Expression of a single transfected cDNA converts fibroblasts to myoblasts. Cell 51: 987-1000

DiPersio, C.M., D.A. Jackson, and K.S. Zaret. 1991. The extracellular matrix coordinately modulates liver transcription factors and hepatocyte morphology. Mol. Cell. Biol. 11: $4405-4414$

Duncan, S.A., K. Manova, W.S. Chen, P. Hoodless, D.C. Weinstein, R.F. Bachvarova, and J.E. Darnell Jr. 1994. Expression of transcription factor HNF-4 in the extraembryonic endoderm, gut, and nephrogenic tissue of the devcloping mouse embryo: HNF-4 is a marker for primary endoderm in the implanting blastocyst. Proc. Natl. Acad. Sci. 91: 7598-7602.

Edmondson, D.G. and E.N. Olson. 1989. A gene with homology to the myc similarity region of MyoDl is expressed during myogenesis and sufficient to activate the muscle differentiation program. Genes \& Dev. 3: 628-640.

Freytag, S.O., D.L. Paielli, and J.D. Gilbert. 1994. Ectopic expression of the CCAAT/enhancer-binding protein $\alpha$ promotes the adipogenic program in a variety of mouse fibroblastic cells. Genes \& Dev. 8: 1654-1663.

Fukuda-Taira, S. 1981. Hepatic induction in the avian embryo: Specificity of reactive endoderm and inductive mesoderm. $/$. Embryol. Exp. Morphol. 63: 111-125.

Gannon, M. and D. Bader. 1995. Initiation of cardiac differentiation occurs in the absence of anterior endoderm. Develop ment 121: 2439-2450.
Ghosh, D. 1990. A relational database of transcription factors. Nucleic Acids Res. 18: 1749-1756.

Gilbert, S.F. 1994. Developmental biology. Sinauer Associates, Saunderland, MA.

Gittes, G.K. and W.J. Rutter. 1992. Onset of cell-specific gene expression in the developing mouse pancreas. Proc. Natl. Acad. Sci. 89: 1128-1132.

Green, H. and O. Kehinde. 1974. Sublines of mouse 3T3 cells that accumulate lipid. Cell 1: 113-116.

Gurdon, J.B. 1988. A community effect in animal development. Nature 336: 772-774.

Herman, R.K. and E.M. Hedgecock. 1990. Limitation of the size of the vulval primordium of Caenorhabditis elegans by lin15 expression in surrounding hypodermis. Nature 348: 169171.

Houssaint, E. 1980. Differentiation of the mouse hepatic primordium. I. An analysis of tissue interactions in hepatocyte differentiation. Cell Differ. 9: 269-279.

Hu, J. and H.C. Isom. 1994. Suppression of albumin enhancer activity by H-ras and AP- 1 in hepatocyte cell lines. Mol. Cell Biol. 14: 1531-1543.

Jackson, D.A., K.E. Rowader, K. Stevens, C. Jiang, P. Milos, and K.S. Zaret. 1993. Modulation of liver-specific transcription by interactions between hepatocyte nuclear factor 3 and nuclear factor 1 binding DNA in close apposition. Mol. Cell. Biol. 13: 2401-2410.

Jackson, J.R. and Benyajati. 1993. DNA histone interactions are sufficient to position a single nucleosome juxtaposing Drosophila Adh adult enhancer and distal promoter. Nucleic Acid Res. 21: 957-967

Lai, E., V.R. Prezioso, W. Tao, W.S. Chen, and J.E. Darnell Jr. 1991. Hepatocyte nuclear factor $3 \mathrm{~A}$ belongs to a gene family in mammals that is homologous to the Drosophila homeotic gene fork head. Genes \& Dev. 56: $416-427$.

Lai, E., K.L. Clark, S.K. Burley, and J.E. Darnell Jr. 1993. Hepatocyte nuclear tactor $3 /$ fork head or "winged helix" protcins: A tamily of transcription factors of diverse biologic function. Proc. Nati. Acad. Sci. 90: 10421-10423.

Le Douarin, N. 1964. Etude expérimentale de l'organogenèse du tube digestif et du fore chez l'embryon de poulet. Bull. Biol. Fr. Belg. 98: 543-676.

- 1975. An experimental analysis of liver development. Med. Biol. 53: 427-455.

Lichtsteiner, S., J. Wuarin, and U. Schibler. 1987. The interplay of DNA-binding proteins on the promoter of the mouse albumin gene. Cell 51: 963-973.

Liu, J.-K., Y. Bergman, and K.S. Zaret. 1988. The mouse albumin promoter and a distal upstream site are simultaneously DNase I hypersensitive in liver chromatin and bind similar liver abundant factors in vitro. Genes \& Dev. 2: 528-541.

L.ju, J.-K., C.M. Dipersio, and K.S. Zaret. 1991. Extracellular signals that regulate liver transcription factors during hepatic differentiation in vitro. Mol. Cell. Biol. 11: 773-784.

McGhee, J.D. and G. Felsenfeld. 1979. Reaction of nucleosome [DNA with dimethylsulfate. Proc. Natl. Acad. Sci. 76: 21332137.

McPherson, C.E., E.-Y. Shim, D.S. Friedman, and K.S. Zaret. 1993. An active tissue-specific enhancer and bound transcription factors existing in a precisely postioned nucleosomal array. Cell 75: 387-398.

Monaghan, A.P., K.H. Kaestner, E. Grau, and G. Schütz. 1993. Postimplantation expression patterns indicate a role for the mouse fork head/HNF- $3 \alpha, \beta$, and $\gamma$ genes in determination of the definitive endoderm, chordamesoderm and neuroectoderm. Development 119: 567-578.

Mueller, P.R. and B. Wold. 1989. In vivo footprinting of a muscle 
specific enhancer by ligation mediated PCR. Science 246: $780-786$.

Pinkert, C.A., D.M. Ornitz, R.L. Brinster, and R.D. Paimiter 1987. An albumin enhancer located $10 \mathrm{~kb}$ upstream functions along with its promoter to direct efficient, liver-specific expression in transgenic mice. Cienes \& Dev. 1: 268276.

Rappolee, D.A., D. Mark, M.J. Banda, and Z. Werb. 1988 Wound macrophages express TGF-alpha and other growth factors in vivo: Analysis by mRNA phenotyping. Science 241: $708-$ 712.

Rhodes, S.J. and S.F. Konieczny. 1989. Identification of MRF4: A new member of the muscle regulatory factor gene family. Genes \& Dev. 3: 2050-2061.

Rigaud, G., J. Roux, R. Pictet, and T. Grange. 1991. In vivo footprinting of rat TAT gene: Dynamic interplay between the glucocorticoid receptor and a liver-specific factor. Cell 67: $977-986$.

Rugh, R. 1968. The mouse: Its reproduction and development Burgess Publishing Company, Minneapolis, MN.

Sasaki, H. and B.L.M. Hogan. 1993. Differential expression of multiple fork head related genes during gastrulation and pattern formation in the mouse embryo. Development 118: 47 59 .

Sassoon, D.A., 1. Garner, and M. Buckingham. 1988. Transcripts of $\alpha$-cardiac and $\alpha$-skeletal actins are early markers for myogenesis in the mouse embryo. Development 104: 155-164.

Schmid, P. and W.A. Schulz. 1990. Coexpression of the C-MYC protooncogene with $\alpha$-fetoprotein and albumin in fetal mouse liver. Differentiation 45: 96-102.

Shiojiri, N. 1981. Enzymo- and immunocytochemical analyses of the differentiation of liver celis in the prenatal mouse. $/$. Embryol. Exp. Morphol. 62: 139-1.52.

Shiojiri, N., J.M. Lemire, and N. Fausto. 1991. Cell lineages and oval cell progenitors in rat liver development. Cancer Res. 51: $2611-2620$

Slack, J.M.W. 1991. From egg to embryo: Regional specification in early development. Cambridge University Press, Cambridge, UK.

Sladek, F.M., W. Zhong, E. Lai, and J.E. Darnell Jr. 1990. Liver enriched transcription factor HNF.4 is a novel member of the steriod hormone receptor superfamily. Genes \& Dev. 4: $2353-2364$.

Sternberg, P.W. 1988. Lateral inhibition during vulval induction in Caenorhabditis elegans. Nature 335: 551-554.

Theiles, K. 1989. The house mouse. Springer-Verlag, New York, NY.

Tilghman, S.M. and A. Belayew. 1982. Transcriptional control of murine albumin/ $\alpha$-fetoprotein locus during development. Proc. Natl. Acad. Sci. 79: 5254-5257.

Tontonoz, P., E. Hu, and B.M. Spiegelman. 1994. Stimulation of adipogenesis in fibroblasts by PPARg2, a lipid-activated transcription factor. Cell 79: 1147-1156.

Tyner, A.L., R.S. Godbout, R.S. Compton, and S. Tilghman. 1990. The ontogeny of $\alpha$-fetoprotein gene expression in the mouse gastrointestinal tract. I. Cell Biol. 110:915-927.

Weigel, D., G. Jürgens, F. Küttner, E. Seifert, and H. Jäckle. 1989. The homeotic gene fork head encodes a nuclear protein and is expressed in the terminal regions of the Drosophila em. bryo. Cell 57: 645-658.

Weinstein, D.C., A. Ruiz i Altaba, W.S. Chen, P. Hoodless, V.R. Prezioso, T.M. Jessell, and J.E. Darnell Jr. 1994. The wingedhelix transcription factor $H N F-3 \beta$ is required for notochord development in the mouse embryo. Cell 78: 575-588.

Wessells, N.K. 1977. Tissue interaction and development. Benjamin, Menlo lark, NY.
Wilkinson, D.G. 1993. In situ hybridization. In Essential developmental biology: A proctical approach led. C.D. Stern and P.W.H. Holland), pp. 257-274, IRL Press, Oxford, UK.

Wright, W., D.A. Sassoon, and V.K. Lin. 1989. Myogenin, a factor regulating myogenesis, has a domain homologous to MyoD. Cell 56: 607-617.

Yelandi, A.V., X. Tan, R.S. Dwivedi, V. Subbarao, Smith, D.F. Scarpelli, M.S. Rao, and 1.K. Reddy. 1990. Coexpression of glutamine synthetase and carbamoylphosphate synthase I genes in pancreatic hepatocytes of rat. Proc. Natl. Acad. Sci. 87: 881-885.

Zaret, K.S. 1995. Nucleoprotein architecture of the albumin transcriptional enhancer. Sem. Cell Biol 6: 209-218.

. 1996. Molecular genetics of early liver development. Ann. Rev. Physiol. 58: 231-251.

Zaret, K.S. and K.A. Stevens. 1993. Primer extension analysis of RNA. Methods Mol. Genet. 2: 342-351.

- 1995. Expression of a highly unstable and insoluble transcription factor in Eschenchia coll: Purification and characterization of the fork head homolog HNF $3 \alpha$. Protein Expression Punification 6: 821-825.

Zaret, K.S., J.-K. Liu, and C.M. DiPersio, 1990. Site-directed mutagenesis of the albumin transcriptional enhancer with the polymerase chain reaction. Proc. Natl. Acad. Sci. 87: 5469-5473.

Zhong, W., F.M. Sladek, and J.E. Darnell, Jr. 1993. The expression pattern of a Drosophila homolog to the mouse transcription factor HNF-3 suggests a determinative role in gut formation. EMBO /. 12: $537-544$. 


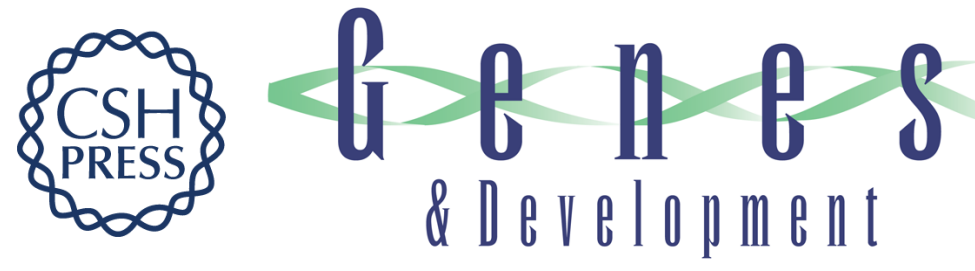

\section{Hepatic specification of the gut endoderm in vitro: cell signaling and transcriptional control.}

R Gualdi, P Bossard, M Zheng, et al.

Genes Dev. 1996, 10:

Access the most recent version at doi:10.1101/gad.10.13.1670

References This article cites 58 articles, 28 of which can be accessed free at:

http://genesdev.cshlp.org/content/10/13/1670.full.html\#ref-list-1

License

Email Alerting

Service

Receive free email alerts when new articles cite this article - sign up in the box at the top right corner of the article or click here.

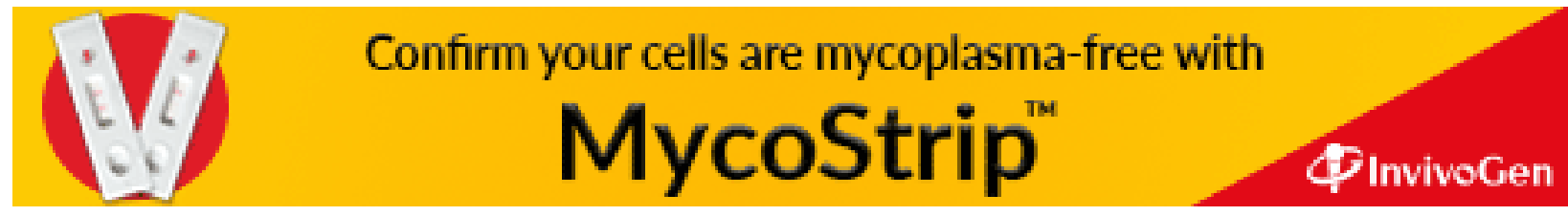

